\title{
REFLEXIONES SOBRE LA NATURALEZA Y LA PRÁCTICA DEL PERDÓN EN EL CONTEXTO DOCTRINAL NO-TEÍSTA DEL BUDISMO. ${ }^{1}$
}

\author{
Reflections on the Nature and Practice of Forgiveness in the Non-Theist Doctrinal \\ Context of Buddhism
}

Profesor Gonzalo Ulloa Rübke

Instituto de Ciencias Religiosas

Pont. Universidad Católica de Valparaíso.

E-mail: ulloargonzalo@gmail.com

\section{RESUMEN}

El Presente artículo trata del concepto del perdón a interior del pensamiento budista entendido este como "una manera de prevenir pensamientos negativos, y por tanto, dañinos, perjudiciales para la paz, la tranquilidad y la salud mental del individuo". La práctica del perdón debe ir necesariamente acompañada de sentimientos de amorcompasión hacia el ofensor y no motivado por un sentimiento egoísta por afán de conseguir admiración por el acto de perdonar. Este difícil acto ayuda al crecimiento personal de quien otorga el perdón.

PALABRAS CLAVES: Budismo, perdón, Buda, samsara, nirvana.

\begin{abstract}
This article deals with the concept of forgiveness within Buddhist thought understood this concept as "a way to prevent negative thoughts, and therefore harmful, detrimental to peace, tranquility and mental health of the individual." The practice of forgiveness must necessarily be accompanied by feelings of love and compassion toward the offender and not motivated by a selfish desire to get admiration for the act of forgiving. The act of forgiveness is a difficult one but it is at the same time an important act of personal growth..
\end{abstract}

\footnotetext{
${ }^{1}$ Publicado en Cuadernos Judaicos N²8, diciembre 2011.
} 
KEYWORDS: Buddhism, forgiveness, Buddha, samsara, nirvana.

\section{INTRODUCCIÓN}

"Según la doctrina nadie - ni siquiera Dios, ni un santo - puede absolver al ser humano de los malos efectos de sus propias acciones. La labor de emancipación es indelegablemente individual, y el Buda, en este aspecto, sólo se limitó a señalar el Sendero. Ninguna intervención arbitraria de terceros puede significar expiación, pues ello alteraría el riguroso principio de la justicia que rige el universo. En el orden personal,cada cual se erige en su propio salvador o destructor."

(Saddhamanda Bikkhu, Diccionario Budista, Buenos Aires, Distar Libros SRL, 1978, 310 pp., Voz “Absolución”, p. 12.

El texto citado, si bien es sólo una concisa explicación en un diccionario, pone en su lugar contextual el tema del perdón en el Budismo, pues se enfatiza la importancia de la responsabilidad individual y "la ley" de la justicia universal que no es sino el resultado del principio de la interdependencia de todas las cosas y de la impermanencia y caducidad absoluta de todo en el universo. Lo anterior implica, a su vez, el principio de la compensación de los actos de los seres sintientes o conscientes, principalmente del ser humano. Este tema implica la doctrina del karma, idea y vocablo mal entendidos y mal usados en occidente, pues en nuestro medio suele ser utilizado como sinónimo de fatalidad en un sentido determinista, que suprime la libertad humana.

Ahora bien, de manera similar a como sucede en todas las tradiciones religiosas y de sabiduría, es preciso distinguir entre aquello que constituye el corpus doctrinal recibido de los fundadores, y aquello que constituye la tradición y la praxis de los creyentes. El Budismo no es una excepción, pues, por una parte, en lo referido al perdón, la doctrina enseña lo que resumidamente señala el texto citado más arriba. Por su parte, el practicante budista (sadhaka) toma refugio en las "Tres Joyas" (triratna): en el Buda histórico (Siddharta Gautama), en el Dharma (la "ley", la enseñanza o doctrina) y en la Sangha (la 
comunidad de creyentes), que son las tres realidades que todo budista debe venerar y servir y que están dotadas del poder de ayudar al creyente a librarse del sufrimiento y guiarlo a la iluminación (Nirvana).

En el contexto general de la doctrina la noción de perdón aparece como uno de los resultados de la gestación por parte del creyente de la mente boddhichitta, esto es, una mente amorosa-compasiva, una actitud pura, iluminada; en este contexto, quien desarrolla este nivel de desarrollo espiritual estará abierto y en disposición de perdonar a quienes le ofendan o sean sus adversarios, o sus enemigos; tal actitud de perdón constituirá un acto altamente meritorio. Existe una boddhichitta relativa y una boddhichitta absoluta; la primera es un resultado natural de la práctica de la meditación, la que genera la compasión amorosa hacia todos los seres sintientes (sensibles o conscientes). Es esta boddhichitta relativa la que conduce a la boddhichitta absoluta, la que constituye la naturaleza última de la realidad, plena de compasión espontánea y amorosa y compasiva que abarca a todos los seres del universo intentando ayudarlos a conseguir la liberación definitiva del samsara, esto es, del ciclo de renacimientos, para alcanzar el Nirvana, es decir, el Absoluto.

Estos párrafos introductorios no estarían completos si omitiéramos mencionar un punto central de la doctrina budista que es la afirmación de que todos los seres del universo poseen la potencialidad interna para alcanzar la Budeidad, esto es, la naturaleza búdica, aunque su consciencia oscurecida por la ignorancia espiritual y un mal karma le dificulten y demoren alcanzar la suficiente sabiduría para percibir esa potencialidad así como la voluntad para desarrollar la inherente naturaleza búdica y alcanzar finalmente la iluminación.

Todo lo comentado hasta este punto permite comprender en su adecuado contexto una práctica muy utilizada en el budismo de tradición tibetana que consiste en que el creyente, postrado ante una imagen del Buda (imagen que puede ser sólo visualizada mentalmente), declara en voz alta aquellos actos no meritorios (en lenguaje cristiano se diría "actos pecaminosos") sean estos de acción u omisión tanto a nivel físico como mental. La 
declaración o enumeración de tales actos debe referirse a toda la vida del individuo, desde que tenga memoria del período de la infancia, hasta el momento de esta práctica. Aunque sea obvio, hay que precisar que tal práctica debe realizarse en la más absoluta privacidad y soledad; normalmente se hace durante un período de tiempo que puede ser de días o de meses, según las circunstancias y disponibilidad personal.

Si reflexionamos acerca de este acto de confesar las propias acciones no meritorias ante una imagen del Buda, surge la pregunta acerca del papel que desempeña Buda en este ritual, pues si se tiene a la vista el carácter no-teísta del Budismo, en rigor tal imagen jugaría un rol solamente simbólico, al modo de un "soporte psicológico" para el practicante. Sin embargo, teniendo a la vista que a lo largo de los siglos transcurridos desde la predicación del Buda su persona fue literalmente divinizada en gran parte de las diversas escuelas y tradiciones budistas, podemos comprender el acto de "confesión de los pecados" solicitando o esperando ser "perdonado" por el Buda.

A mayor abundamiento, es preciso subrayar que junto con el proceso de divinizar a su fundador, el Budismo Mahayana menciona en muchos rituales no sólo la doctrina de los "trikaya" o de los tres cuerpos del Buda i, i sino además los conceptos de "campos búdicos" y de "paraísos" situados en mundos espirituales donde se encuentran los Budas de remotas épocas cósmicas, el Buda Shakyamuni (Gautama Siddharta) de la era actual, así como innumerables seres de altísima realización espiritual, como los Boddhisattvas, Mahasidhas y muchos otros seres - masculinos y femeninos - englobados en el concepto de "seres divinos" iii; estos seres - ya plenamente realizados espiritualmente - ayudan amorosamente a sus devotos a avanzar en su desarrollo espiritual. Es también en esta perspectiva donde podemos situar y comprender el acto de verbalizar conscientemente las propias faltas cometidas durante esta vida en la esperanza de "ser perdonados" por el Buda, o por "los Budas".

A partir de los elementos mencionados en los párrafos anteriores reflexionaremos sobre el carácter y real significado del no-teísmo del Budismo y sus consecuencias tanto en algunos aspectos de la doctrina - por ejemplo en la moral - como en la praxis cotidiana 
de los creyentes, y, por cierto de manera más particularizada, en la práctica del perdón. Pues, si se soslaya la figura de una divinidad personal, legisladora y justiciera, será necesario estudiar el lugar que ocupa la noción de perdón en el Budismo, pues, ¿quién [o qué] legisla? ¿quién [o qué] “castiga” al transgresor y “premia” al justo?

De paso recordemos que de las grandes religiones universales, como es el caso de las cuatro monoteístas (Judaísmo, Cristianismo, Islam y Fe Baha’i), es únicamente en el Cristianismo donde el creyente se presenta ante Dios como "pecador", implorando, penitente (e.d., arrepentido), el perdón de Dios. ${ }^{\text {iv }}$

Hay temas conexos que estarán presentes en este tra bajo: el tema ya mencionado de la importancia para el budista de generar en sí mismo una "mente boddhichitta" (de amorcompasión), y el tema de la responsabilidad personal de cara al desarrollo valórico de la propia vida, así como de cara a las relaciones del individuo no sólo con los demás seres humanos, sino con toda la realidad que se podría denominar "externa" a él. Lo anterior conlleva, de suyo, la importancia central que tiene en el Budismo el tema de la naturaleza de la mente, realidad y noción que suele homologarse al concepto de conciencia.

Hecha esta breve introducción, enfrentamos ahora el complejo tema del no-teísmo budista, complejo, pues tiene muchas "aristas", la primera de las cuales es el hecho de que no hay "un" Budismo, pues en dos mil quinientos años se han desarrollado innumerables escuelas y "tradiciones" v a lo largo y ancho de la extensa geografía budista, incluido el ámbito europeo, el norteamericano (México, Canadá y EE.UU.), el centro americano y el sudamericano; también en Australia y Neozelandia hay importantes centros de diversas tradiciones budistas; no tenemos datos del continente africano. A lo anterior hay que agregar las dificultades históricas y epistemológicas para autentificar la genuina doctrina predicada por Siddharta Gautama, el Buda, ${ }^{\text {vi }}$ tema, que, por cierto, no es menor, pues, así como en el mundo académico dedicado a las investigaciones budistas no ha habido nunca unanimidad con relación a lo que se suele denominar "el budismo primitivo", tampoco la ha habido en las numerosas escuelas, tendencias y prácticas religiosas budistas repartidas por el mundo. Más aú n, cuando decimos “escuelas, 
tendencias y prácticas religiosas budistas "..., estamos tocando el espinudo problema que concierne al concepto de "religión"; ¿es, acaso, la "religión" un cuerpo compacto de ortodoxia?, ¿o más bien es una "fe”?, ¿o quizás sólo una singular "praxis"? ¿o más bien todo lo anterior constituye diferentes aspectos de una "misma realidad"? vii

El Profesor Edward Conze ${ }^{\text {viii }}$ dedica varias páginas al tema del Budismo como religión, presentándolo, en primer lugar, como "una forma oriental de espiritualidad" y estableciendo un interesante paralelo con las tradiciones de la ascética y la mística de las tradiciones abrahámicas.

"Lo que se conoce como "budismo" - dice - forma parte de la común herencia humana de sabiduría, por medio de la cual los hombres han logrado superar este mundo y alcanzar la inmortalidad, o una vida sin muerte." (Conze, E., o.c., p. 11).

Y, más adelante, agrega:

"Una religión es una organización de aspiraciones espirituales, que rechazan el mundo sensorial y niegan los impulsos que nos unen a él. Durante 3000 años, sólo Asia ha creado ideas y métodos espirituales. (...) Toda la espiritualidad europea ha tenido que ser renovada periódicamente por algún influjo del Oriente, desde la época de Pitágoras y Parménides. Si separamos los elementos orientales de la filosofía griega, si quitamos a Jesucristo, San Pablo, Dionisio el Areopagita, y el pensamiento árabe, todo el pensamiento espiritual europeo de los últimos dos mil años resulta inimaginable." (Conze, E., ibid., pp. 12-13).

También Keiji Nishitani, de la Escuela filosófica de Kyoto, dedica las cuarenta y ocho páginas del primer capítulo de su obra más importante ${ }^{\mathrm{ix}}$ a responder la pregunta "Qué es la religión”, desarrollando el tema de manera muy sugerente para el lector occidental, principalmente por la interesante confrontación que hace de su propio pensamiento imbuido de budismo con pensadores occidentales desde Platón y Descartes hasta Schleiermacher, Karl Barth y Sartre, pasando por Kant y Kierkegaard. 
Si bien concordamos con las ideas centrales de los autores mencionados y citados, detenernos a discutir el tema del concepto de "religión" nos alejaría de nuestro tema central, por lo que nos limitaremos a señalar grosso modo nuestra particular opinión sobre este punto y que consiste en ver al Budismo al mismo tiempo como un camino de realización personal, tras el logro de la sabiduría, el que, a su vez, implica una necesaria praxis (esto es, un "estilo de vida"), y, también - aunque no necesariamente - un sentido y experiencia de "lo religioso", en la medida que hay - o puede haber -, una proyección a la trascendencia ${ }^{\mathrm{x}}$.

Entonces, frente al variopinto panorama del mundo budista después de aproximadamente 2500 años de historia, la manera más conveniente para evitar ingresar al espeso bosque de las variedades de la doctrina es acercarse al que era el medio espiritual de la India de la zona gangética alrededor del siglo VI antes de la Era Común (a.e.c.), pues esa información, aunque no sea más que de manera general, será significativa $\mathrm{p}$ ara comprender el contexto en que se dio la primera enseñanza por parte de Siddharta Gautama, el Buda, y ver acaso el estado de la antigua religión védica en ese momento pudo haber provocado en el Buda una reacción en cierto modo contestataria, reformista e iconoclasta frente a ella.

En la época en que aparece el Buda (563-483, o bien, 558-478 a.e.c.), la antigua religión védica venía experimentando un lento proceso de decaimiento, una pérdida de su alma, convirtiéndose en un conjunto de complejas técnicas y rituales impregnados de elementos mágicos y supersticiosos, todo ello manejado por la clase privilegiada de los brahmanes, pues es la casta sacerdotal la que se constituye en celosa guardiana de las potencias sobrenaturales; como la eficacia de esos rituales era proporcional a su complejidad y, por qué no decirlo, proporcional también a los honorarios o estipendios que debía pagarse a los sacerdotes encargados de llevarlos a cabo, sólo los brahmanes más ricos, los nobles, los comerciantes y los terratenientes podían darse el lujo no sólo de pagar sino que al mismo tiempo podían abrigar la esperanza de disfrutar de dicha y prosperidad en una indefinida y sucesiva serie de encarnaciones, no así los desheredados de la fortuna, quienes debían esperar sólo renacer en las más penosas condiciones. Es preciso aclarar 
que tales prácticas y pretensiones no cuentan en absoluto con respaldo en las escrituras sagradas del Hinduismo.

Tal situación explica por qué fue en las regiones más alejadas de los centros desarrollados de la civilizada India de esa época donde dieron frutos dos de las religiones más importantes nacidas en el siglo VI a.e.c. desde el seno del Sanatanadharma ${ }^{x i}$ - por cierto consideradas heterodoxas por la casta sacerdotal - y que son el Budismo, nacido a los pies de los Himalayas, y el Jainismo, su contemporáneo, que nace hacia el este, en los confi nes de Bengala.

En el caso del Budismo, el contexto religioso y cultural que hemos mencionado explica por qué el Buda insistió tanto en que lo único importante es terminar con el sufrimiento, incluso de un modo que podríamos llamar pragmático, evitando las especulaciones y discusiones filosóficas o teológicas que distraen de la única meta válida: la extinción del deseo (tanha, sed), que es la causa del sufrimiento, y también evitando la práctica de rituales, los que suelen absolutizarse o mezclarse con supersticiones y elementos mágicos. El Nirvana sólo se logrará controlando la mente de acuerdo con las diversas y ricas metodologías de la enseñanza budista y sintetizadas en el Noble Óctuple Sendero ${ }^{x i i i}$ y en las seis Paramitas o Virtudes ${ }^{\mathrm{xiv}}$.

Por tanto son inútiles preguntas como:

“¿De qué está construido este universo? ¿Es eterno o tiene fin? ¿El universo es infinito o tiene límites? ¿Cómo está construida esta sociedad humana? ¿Cuál es la forma ideal de la sociedad humana? Si alguien pospone la búsqueda y la práctica de la Iluminación hasta que estos problemas se resuelvan, morirá antes de alcanzar la Iluminación.(...) No importa cuál sea la esencia del universo mientras no se practique lo que se debe practicar. No importa cuál sea la forma ideal de la sociedad humana, antes tenemos que apagar el fuego de las pasiones que están amenazando el mundo. El problema de si el universo es eterno o no, infinito o no, es muy secundario mientras vejez, enfermedad, muerte, tristeza, sufrimiento, penas, caen sobre nosotros para destruirnos. Ante todo, debemos practicar el Camino para alejar estos fuegos que se nos 
avecinan." (Majjhima-Nikaya, Chulamalunkya-suttanta, 7-63) ${ }^{\mathrm{xv}}$

Cierto es que a pesar de la claridad de lo expresado en el párrafo citado, en todas las tradiciones del Budismo se fue gestando a lo largo de los siglos un rico acervo de rituales, algunos muy complejos y vistosos, como en el Budismo tibetano, o en el Budismo Shingón de Japón, otros muy simples e incluso iconoclastas, como en algunas formas del Budismo Zen; y, por cierto, los rituales van usualmente relacionados con música e imágenes de todo tipo, estatuaria, pinturas, arquitectura y otras formas del arte, todo ello fruto del hombre inserto en la inevitable inculturación de las enseñanzas en muy diversos ámbitos culturales, que van desde los territorios hindostánicos, hasta China, Japón y el sudeste asiático, sin olvidar las naciones occidentales.

Es teniendo a la vista todo lo dicho hasta ahora que intentaremos sintetizar el significado del no-teísmo budista así como el lugar que ocupa en el cuerpo doctrinal.

Es un hecho que Buda - al menos en los comienzos de la enseñanza del Dharma - no rechazó ni negó la existencia de los dioses objeto de devoción de quienes llegaban a él como discípulos, ni les prohibió continuar sus prácticas religiosas tradicionales; en los Sutras, que son las colecciones de sermones del Buda, podemos encontrar enfáticas referencias a los dioses, por ejemplo, en el Sermón llamado "La puesta en marcha de la Rueda del Dharma” (Dhammachakkappavattanasutta, en el Anguttara Nikaya, LVI, 11):

“...Y cuando el Sublime hizo girar de esta manera la Rueda del Dhamma, los dioses de la tierra exclamaron: 'Esta incomparable Rueda del Dhamma que no podía ser puesta en marcha por ningún otro, ya sea asceta, brahmán, deva, Mara, Bráhma, o sea quien fuere en este mundo, el Sublime la ha hecho girar, en el Parque del Ciervo, en Isipatana, cerca de Benarés. Y esto fue repetido por los dioses de los innumerables reinos celestiales. Y el clamor de estos dioses retumbó hasta el mundo de Bráhma, y los 10.000 mundos temblaron, se estremecieron, fueron violentamente sacudidos, y una inmensurable luz brillante que sobrepasaba la divina majestad de los dioses envolvió el mundo." $x v i$ 
Otro ejemplo lo encontramos al finalizar el texto del "Sutra del Corazón" (Bhagavati Prajñaparamita Hridaya).

"Cuando el Bienaventurado se pronunció de este modo , el venerable Shariputra, el bodhisattva mahasattva, el noble Avalokiteshvara, todos cuantos formaban las asambleas, el mundo de los dioses, los seres humanos, los asuras y los gandharvas se regocijaron y elogiaron abiertamente las palabras del Bienaventurado" „xvii

Como acabamos de decir, es probable que al inicio de su predicación el Buda no hiciera mayor cuestión de los ritos de tradición hinduista que su discípulos continuaban practicando, así como también es probable que quienes pusieron por escrito estos textos provenientes de la tradición oral colocaran en boca del Buda y de sus interlocutores expresiones del lenguaje cotidiano con evidente contenido teísta, pero que debemos interpretar de la misma manera como lo hacemos en la actualidad cuando escuchamos a una persona de reconocido agnosticismo, o incluso de confesado ateísmo, decir, por ejemplo: "Nos veremos la próxima semana si Dios quiere", o frases similares.

En todo caso, hechos los comentarios que anteceden, encontramos numerosos textos en los que Buda insiste en que no le interesa la cuestión de la existencia de "Dios", pero no en el sentido de que esté negando la existencia de ese ser, sino más bien que él decide callar al respecto. Refiriéndose al silencio del Buda como apofatismo, Panikkar dice que

"El llamado "apofatismo" indica generalmente un apofatismo epistemológico: afirma que la última realidad es inefable (aunque se la pueda considerar "inteligible" $e$, incluso, sumamente inteligible "en si') porque no hay inteligencia humana capaz de comprenderla. Mientras que este apofatismo nos habla de una inefabilidad en cuanto a nosotros, "quoad nos", el apofatismo budista pretende llevar la inefabilidad al seno mismo de la última realidad y afirma que esta misma es inefable, inexpresable, incomunicable, porque su "logos", su expresión, su comunicación, ya no pertenece al orden de la última realidad, sino al de su manifestación, no ya en cuanto a nosotros, sino en cuanto tal, "quoad se". El apofatismo budista es un apofatismo óntico a la par que ontológico. La realidad última es de tal manera inefable y transcendente que, en rigor, el budismo, consecuentemente, le negará incluso el carácter de Ser. El Ser es lo que es, pero 
lo que es, por el hecho mismo de ser, es en cierta manera pensable, comunicable, pertenece al orden de la manifestación, del ser, y no puede, por tanto, considerarse como la misma última realidad.

Cuando el Buddha se niega a responder, no es por ningún motivo subjetivo (suyo, del interlocutor o de la naturaleza humana) sino en virtud de una exigencia de la realidad misma: no es un silencio metodológico, ni pedagógico, sino óntico y ontológico . Su silencio no es sólo la respuesta, sino que invade la misma pregunta. No sólo calla, sino que también acalla.” (Panikkar, R. (2000), p. 64 ss. Las negritas son nuestras).

En las religiones teístas es conocida actitud del creyente que al experimentar en su corazón y en su mente que ha "ofendido a Dios", que está “en pecado", acude a ese Dios de su fe pidiendo perdón, clamando misericordia

\footnotetext{
“'Dichoso el que es perdonado de su culpa, y le queda cubierto su pecado!

Dichoso el hombre a quien Yahveh no le cuenta su delito, y en cuyo espíritu no hay fraude.

(...) Mi pecado te reconocí, y no oculté mi culpa; dije: 'Me confesaré a Yahveh de mis rebeldias', Y tú absolviste mi culpa, perdonaste mi pecado”. (Salmo 32 (31).
}

En cambio en el Budismo, en el contexto no teísta que hemos intentado mostrar, el énfasis está colocado, en primer lugar, en la necesidad de asumir la responsabilidad de los propios actos y de las consecuencias que de tales actos se seguirán. De ahí la importancia que se da a la gestación de una mente amorosa y compasiva, la llamada mente boddhichitta, como ya lo hemos explicado más arriba:

"Que la Boddhichitta excelente y preciosa,

Donde no haya nacido, que surja,

Donde haya nacido no decline, sino que aumente más y más"xviii 
Y, puesto que "la condición humana está dirigida por la mente, predomina en ella la mente, está hecha de mente." (Dhammapada, I, 1-2), que la mente es el crisol donde se fraguan todos los actos humanos, sean estos puramente pensados o sean realizados, se concluye que al cambiar la mente común en una mente amorosa ( metta, maitri) y compasiva (karuna), la persona gestará al mismo tiempo una actitud benevolente (bene volere, e. d., "querer bien") hacia todos los seres sintientes.

"Me insultó, me golpeó, me venció, me robó - no cesa la agresividad de aquellos que albergan estos sentimientos de rencor. Me insultó, me golpeó, me venció, me robó - cesa la agresividad de aquellos que no albergan estos sentimientos de rencor. Jamás en este mundo los odios cesan con el odio; cesan con la benevolencia: esta es una ley eterna." (Dhammapada, I, 3-5).

Por tales razones y motivos en el Budismo el perdón es visto como una manera de prevenir pensamientos negativos, y por tanto, dañinos, perjudiciales para la paz, la tranquilidad y la salud mental del individuo. Por cierto, es importante enfatizar que en la práctica budista es indispensable que toda actividad conducente al desarrollo personal, como en este caso la práctica del perdón, debe estar condicionada, motivada, por el amorcompasión hacia quien nos ha ofendido o dañado de cualquier forma. Si no se cumple tal condición y tal acto está, por ejemplo, movido por el egoísta objetivo de ser admirado, o gratificado de alguna manera, entonces ese acto del perdonar, si bien beneficia a quien se perdona, no redundará en beneficio alguno para quien perdona.

Visto el acto de perdonar en el contexto de la llamada "ley del karma", como ley natural de causa y efecto, de acción y reacción, es posible comprender que el que ofende y causa daño, moral o físico es en verdad víctima de sus pasiones y tendrá que asumir conscientemente o no - los resultados "kármicos" de sus actos. Por el contrario, quien practica el perdón con amor y compasión por el otro, consciente o inconscientemente estará acumulando méritos que madurarán en resultados "kármicos" positivos, beneficiosos, auspiciosos. En definitiva, si no perdonamos a quienes nos ofenden, nos iremos identificando con nuestro dolor, o con nuestro rencor u odio, lo cual redundará, repetimos, en resultados kármicos negativos. 
En este mismo sentido, en cuanto el perdonar enriquece a quien perdona e inspira a quien recibe el perdón, es pertinente recordar lo que se dijo en los párrafos introductorios de este trabajo, cuando se mencionó la práctica recomendada en la tradición del Budismo tibetano de expresar en voz alta un elenco de los propios actos no meritorios cometidos durante toda la vida hasta el presente; pues bien, ello se complementa muy bien con la práctica llamada tong len, también de la tradición budista tibetana; el vocablo "tong len" puede traducirse como la práctica de "dar y recibir ", y que consiste en que el practicante se coloca en una posición estable y cómoda, que puede ser la que se utiliza para la meditación, concentrándose en la persona o personas a las que se desea ayudar, pues están pasando por una situación concreta de sufrimiento, por ej., un niño agredido, un enfermo grave o terminal, alguien reconocidamente agresivo, amargado, depresivo, etc.; enseguida, siguiendo el ritmo natural de la respiración, de inhalación y exhalación se solidariza con el sufrimiento o emoción negativa de esa persona y, al exhalar, con sentimientos de amor y compasión se le envía la sensación de relajación o aquello que se cree que producirá en esa persona curación, alivio, tranquilidad, felicidad, o cualquier otro sentimiento o sensación positiva. Puede suceder que esta práctica resulte difícil, o, incluso imposible, pues el practicante se enfrenta a sus propios miedos o angustias, por lo cual deberá primero enfocarse en sí mismo y sus miedos, uniéndose solidariamente a todos aquellos que en el mundo están experimentando ese mismo estancamiento o negatividad. Este proceso de "tong len" ayuda al practicante a liberarse del egoísmo, ayuda a sentir amor por uno mismo y por los demás, y así a ocuparnos también de los demás. Es una forma de "perdonar"; recordemos que "perdonar" tiene que ver con el "dar".

.En síntesis, hay en el Budismo una serie de conceptos estrechamente relacionados con el amor (Metta) y que son la virtud de la compasión [que implica el "sentir-con”] (Karuna), la de la alegría simpatética (mudita), y la ecuanimidad (upekkha).

\section{A MODO DE CONCLUSIÓN.}

En contraste con las religiones teístas, especialmente el Cristianismo, en las cuales nada 
se explica sin acudir a la existencia de un Dios creador, justiciero pero amoroso, clemente y misericordioso, en el Budismo, por el contrario, todo se explica sin necesidad de acudir a la idea de un Dios-Persona y creador. Sin embargo, hay que recordar que el no-teísmo budista hay que comprenderlo en el ámbito del apofatismo, en el callar acerca de Dios, no en el frecuente malentendido que ve al Budismo como un ateísmo que niega la existencia de un Dios.

"La mística, en general, busca el silencio. La fuerza del poder con la que tiene que ver es tan grande que sólo el silencio puede darle una "ocasió n”. Ésta es la "paradoja” de la expresión de la que habla Karl Jaspers: se querría decir todo lo que hay que decir y algo más; la mayor elocuencia alterna con el silencio total." ${ }^{\text {xix }}$

A su vez, Juan de Yepes, más conocido como San Juan de la Cruz, declara:

"La mayor necesidad que tenemos es de callar a este gran Dios con el apetito y con la lengua, cuyo lenguaje, que Él oye solo, es el callado amor. "xx

A mayor abundamiento, otro ejemplo lo encontramos en una breve anécdota súfi:

"Los discípulos tenían munlitud de preguntas que hacer acerca de Dios. Les dijo el Maestro: 'Dios es el Desconocido y el Incognoscible. Cualquier afirmación acerca de Él, cualquier respuesta a vuestras preguntas no será más que una distorsión de la Verdad.' Los discípulos quedaron perplejos: 'Entonces, ¿por qué hablas sobre Él?' '¿Y por qué canta el pájaro?', respondió el Maestro. "xxi

Es así como el no-teísmo budista, cuyo silencio acerca de un Dios-persona y creador - al menos entendido desde la concepción judeo-greco-cristiana (ver la nota $n^{\circ} 3$, al final) sólo puede explicarse en el ámbito cultural, doctrinal y psicológico budista el que, a su vez, coloca en su adecuado contexto el acto de perdonar y ser perdonado.

En el Budismo, quien perdona es el principal beneficiario de tal acto movido por el amor- 
compasión. El perdón es así uno de los aspectos de una sabiduría liberadora y se relaciona, al mismo tiempo, con la convicción budista de que todo en el universo está interrelacionado, interdependiente, lo que lleva a vivir las relaciones interpersonales con las convicción de que las diferencias entre las personas son muchísimo menores de lo que imaginamos, lo que conduce a su vez a la vivencia de "estar-en-el-mundo" con más lucidez y sabiduría. 


\section{NOTAS}

i. No hay otros datos del autor. El título de "Bikkhu" (=monje) a continuación del nombre es frecuente en los monjes del Budismo Theravada; tampoco se menciona lengua original y traductor, si lo hubiere.

ii. Los tres cuerpos (trikaya) del Buda son el "Nirman akaya" o "cuerpo de manifestación" o "cuerpo físico", el "Dharmakaya" o "cuerpo de doctrina" y el "Sambhogakaya" o "cuerpo trasfigurado" o "trascendente".

iii. Es preciso aclarar que en el contexto asiático, especialmente en el Hinduismo y en el Budismo, el vocablo "dios" y sus derivados es traducción del sánscrito "deva" que por su raíz "dev-" implica el concepto de "luminoso", "ser de luz", por tanto no hay correspondencia con el concepto de "dios" en el contexto y sentido aristotélico-tomista que concibe a "dios" como un ser absoluto, único, y, más aún, como "persona”; entonces, en el ámbito asiático no abrahámico no es problema hablar de "dioses" o "seres divinos", así , en plural

iv. Por ejemplo, en el Judaísmo el hombre se presenta ante Dios como "socio" como resultado del Pacto que ha hecho Dios con su pueblo elegido; en el Islam en cambio, el hombre se presenta ante Dios como su "devoto y fiel servidor".

v. Evito el vocablo "secta", que todavía hoy suelen utilizar algunos autores, debido a la carga negativa que ha ido adquiriendo este término en la actualidad; más aún, en el mundo budista las variadas escuelas y tradiciones son "diversas, pero no adversas", no existiendo rivalidad ni contradicciones doctrinales entre ellas.

vi. Cf. Panikkar, R. (2000), p. 54

vii. Cf. Panikkar, R. (2000), y, muy especialmente Cantwell Smith, W. (1962), pp. 19-49

viii. Conze, E. (1959), pp.11-15; ed. en cast., pp. 11-17

ix. Nishitani, K., (1999), pp. 37-84.

x. Cf. Küng, H. (1986), p. 7-12

xi. En sánscrito: "la doctrina (o Ley) eterna", término que designa a las varias tradiciones religiosas que en Occidente designamos con el 
vocablo "Hinduismo".

xii. $\quad$ Cf. Bareau, A. (1962), p. 9 ss.; Cf. también Arvon, H. (1966), p. 11 ss.

xiii. Recto esfuerzo, recta atención, recta concentración, rectas palabras, recta acción, rectos medios de vida, recto pensamiento y recta comprensión.

xiv. La generosidad, la moralidad, la paciencia, el entusiasmo, la meditación y la sabiduría.

xv. Bukkyo Dendo Kyokai (2001), p. 150.

xvi. Según traducción de Lachassagne, G. (1959), p. 35. Las negritas son nuestras.

xvii. Según traducción de Mestanza i García, F. 2001), p. 11. Las negritas son nuestras.

xviii. Invocación tradicional de antigua data muy utilizada por los devotos budistas.

xix. G. Van der Leeuw (1964), p. 417 infra.

xx. San Juan de la Cruz (1964), p. 976.

xxi. Anthony de Mello (1982), p. 16

\section{REFERENCIAS BIBLIOGÁFICAS:}

ARVON, Henri. Le Bouddhisme. $5^{\text {a }}$ ed. francesa, Paris, Ed. Presses Universitaire de France. 1966, 128 pp.

BAREAU, André. Bouddha, 1ª ed. francesa, Paris, Ed. Seghers, coll. "Philosophes de Tous les temps". 1962. $223 \mathrm{p}$.

BUKKYO DENDO KYOKAI ("BDK”: Fundación para la promoción del Budismo). La enseñanza de Buda. $9^{a}$ ed. castellana (traductor desconocido). Tokyo,Ed. BDK. 2001, 309 p.

CANTWELL SMITH, Wilfred. The meaning and end of religión. A new appoach to the Religious Tradition of Mankind. First printing in Mentor Book, New York. Ed. Macmillan Co. 1964, $352 \mathrm{p}$. 
CONZE, Edward. Buddhism: its essence and development. New York. 1959. Ed. Harper Torchbook. 236 p. [Hay ed. castellana, $1^{a}$ ed.castellana, (traducción de Flora Botton-Burlá sobre la ed. original en inglés),1978, Mexico. Ed. Fondo de Cultura Económica (FCE), col. Breviarios, $\mathrm{n}^{\mathrm{o}} 275,317 \mathrm{p}$.]

DRAGONETTI, Carmen. (trad.) Dhammapada. El camino del Dharma. $1^{\text {a }}$ ed. castellana (Traducción directa de la lengua pali, introducción y notas de Carmen Dragonetti). Buenos Aires. Ed. Sudamericana, 1967. 247 p.

KENCHEN SHERAB, Rimpoché y DONGYAL y Tsewang Rimpoché. El Sutra del Corazón. $1^{\text {a }}$ ed. castellana (traducción del inglés, revisión del tibetano del texto del sutra, notas y glosario de Ferrán Mestanza i García). Barcelona. Ed. Kairós. 2003. 128 p.

KÜNG, Hans. "Debate sobre el término religión”, revista Concilium ( $n^{\circ}$ 203): pp. 7- Enero 1986.

LADNER, Max, y LACHASSAGNE, G. La enseñanza del Buda. Con una antología de textos pali. $1^{a}$ ed. castellana (trad. De HERMANN Y Virginia M.Erhart sobre la ed. original alemana). Buenos Aires. Ed. La Mandrágora, col. Asoka, 1959. 84 pp.

NISHITANI, Keiji. La religión y la nada. $1^{\text {a }}$ ed. castellana (trad. De Raquel Bouso García sobre la $1^{a}$ ed. en inglés, de 1982 y que fuera revisada por K. Nishitani). Madrid. Ediciones Siruela. 1999, $379 \mathrm{p}$.

PANIKKAR, Raimón. El silencio del Buddha. Una introducción al ateísmo religioso. $5^{\mathrm{a}}$ ed. castellana. Barcelona. Ed. Siruela, 2000, 423 p.

SADDHAMANDA, Bhikkhu. Diccionario Budista. (Traductor desconocido). Buenos Aires. Ed. Distar Libros. 1978, 310 p.

SOKA GAKKAI. Dictionary of Buddhism. Tokyo. Ed. by Soka Gakkai. 2002. 979 p. 